\title{
The effect of silica nanoparticle aggregates on wax dissolution in diesel oil
}

\author{
Sun Renyuan", Wang Lei ${ }^{2}$, Sun $\mathrm{Chao}^{3}$, Lin $\mathrm{Li}^{1}$ and Jiang Hanqiao ${ }^{4}$ \\ ${ }^{1}$ School of Petroleum Engineering, China University of Petroleum, Qingdao, Shandong 266555, China \\ ${ }^{2}$ Institute of Drilling \& Production Technology, Jidong Oilfield, Tangshan, Hebei 063004, China \\ ${ }^{3}$ Xianhe Oil Production Plant, Shengli Oilfield, Dongying, Shandong 257000, China \\ ${ }^{4}$ School of Petroleum Engineering, China University of Petroleum, Beijing 102249, China \\ (C) China University of Petroleum (Beijing) and Springer-Verlag Berlin Heidelberg 2011
}

\begin{abstract}
In recent years, silica nanoparticle aggregates (SNPAs) have been used to decrease the injection pressure of wells in low permeability reservoirs achieving good results. In order to study the mechanisms for reduction in the injection pressure of low permeability wells by the SNPA-diesel oil system injection, the microstructure of SNPAs was observed with a transmission electron microscope (TEM). The particle size distribution of SNPAs was also measured by the laser scattering method. The viscosities of diesel oil and SNPA-diesel oil system were measured with a capillary viscometer. The effect of SNPAs on the solubility of wax in the diesel oil was experimentally studied. The influencing factors, including temperature and SNPA concentration in diesel oil, on wax solubility were analyzed. A pore-throat film displacement model (PTFDM) was built for mechanism explanation. The microstructure and size distribution analyses show that the SNPAs are in the nanometer size range. The viscosity of the SNPA-diesel oil system is lower than that of the diesel oil. The solubility of wax in the diesel oil increases greatly due to SNPA addition, the solubility ratio reaches 7.5. The solubility of wax in diesel oil increases with increases in the concentration of SNPAs in the diesel oil and with the temperature. It is proved that the addition of SNPAs to diesel oil helps remove the wax deposited near the wellbore. This maybe one of the main mechanisms for injection pressure decreases in low permeability reservoirs.
\end{abstract}

Key words: Silica nanoparticle aggregates, solubility of wax, low permeability reservoir, pore-throat film displacement model, injection pressure

\section{Introduction}

Silica nanoparticle aggregates (SNPAs), are inorganic powders with high specific surface area and a large number of unsaturated bonds. $\mathrm{SiO}_{2}$ nanoparticles have been used in a wide range of applications, such as paper coating additives and polymerization (Huang et al, 1995; Qing et al, 2000; Jin et al, 2002; Yuan et al, 2006). Silica nanoparticle aggregates (SNPAs) are aggregates of $\mathrm{SiO}_{2}$ nanoparticles, and their surfaces are chemically modified with methyl alkane or dimethyl alkane under X-ray radiation.

In recent years, SNPAs have been used for decreasing the injection pressure in low permeability reservoirs. Experimental studies and field tests have been conducted (Ju et al, 2002; Su et al, 2002; Lu et al, 2003; Yang et al, 2003; Zhang et al, 2003; Gao, 2004; Hong, 2004; Chen et al, 2005; Liu et al, 2005; Yi et al, 2005; Cheng et al, 2006; Lü and Zhang, 2006; Sun and Wang, 2008). The fluid carrying SNPAs from the surface to the bottom of the injection well

*Corresponding author. email: sunrenyuan@126.com

Received July 28, 2010 is diesel oil. The main reasons for a decrease in injection pressure are the rock wettability change and the increase in the water relative permeability (Ju et al, 2002; Su et al, 2002; Hong, 2004; Cao et al, 2005). Up to now, studies (Ju et al, 2002; Su et al, 2002; Hong, 2004; Cao et al, 2005) can explain neither the excellent results nor the failure for some wells.

The oil produced from low permeability reservoirs often contains wax. The oil production is seriously affected by wax precipitation near the wellbore. Liu et al (2005) studied the effect of SNPAs on the solution of organic blocking material (such as asphalt). In our earlier study (Sun and Wang, 2008), the microstructure of SNPAs was observed and the effect of SNPAs on diesel oil viscosity and clay swelling was studied. In this study, the size distribution of SNPAs in diesel oil was measured and the effect of SNPAs on wax dissolution in diesel oils was experimentally studied.

\section{Experimental}

\subsection{Materials}

Powdered silica nanoparticle aggregates (SNPAs) were 
provided by the Research Institute of Geological Science, Shengli Oilfield. The $\mathrm{SiO}_{2}$ content in the powders was more than $80 \%$ and its mass loss was about $10 \%$ after a thermal treatment at $950{ }^{\circ} \mathrm{C}$ for $2 \mathrm{~h}$. Its density was $150.0 \mathrm{~kg} / \mathrm{m}^{3}$ and its specific surface area was more than $110.0 \mathrm{~m}^{2} / \mathrm{g}$. Diesel oil, wax and distilled water were also used.

\subsection{Methods}

1) The microstructure of SNPAs was observed with a transmission electron microscope (TEM) in the Hebei University of Technology.

2) The size distribution of SNPAs in diesel oil was measured using the Zetasizer equipment made by Malvern Company (UK).

3) The viscosities of diesel oil and SNPA-diesel oil system were measured with a capillary viscometer.

4) A setup, as shown in Fig. 1, was developed for measuring the solubility of wax in diesel oil and SNPA-diesel oil system at different temperatures.

Measurements of solubility of wax in the diesel oil and in the SNPA-diesel oil system were performed in a cylinder, which was immersed in a temperature controlled water-bath. The weight of wax before and after solubility testing was measured with an electronic balance. When the temperature of the water-bath was kept constant, $100 \mathrm{~mL}$ diesel oil or SNPAs-diesel oil was put in the cylinder, then the wax was added slowly to the cylinder. When the wax did not dissolve in the solution, the remaining wax was weighted. Thus the wax dissolved in the diesel oil or in the SNPA-diesel oil system can be calculated.

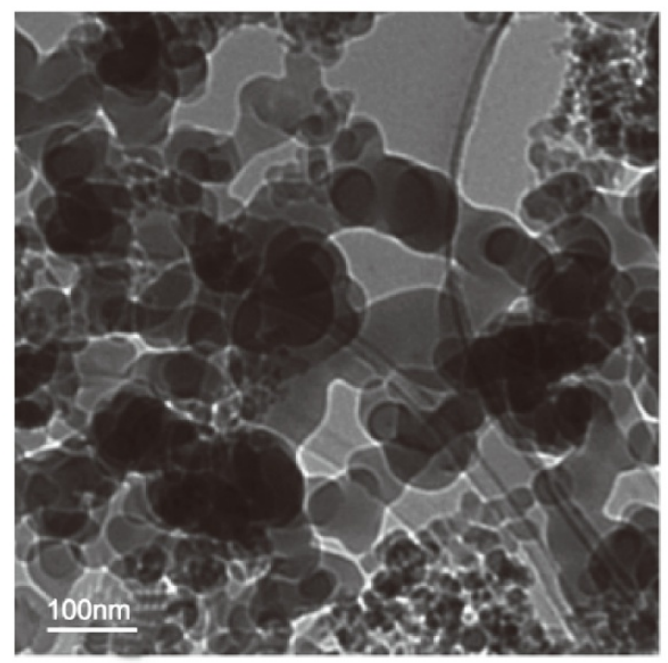

(a)

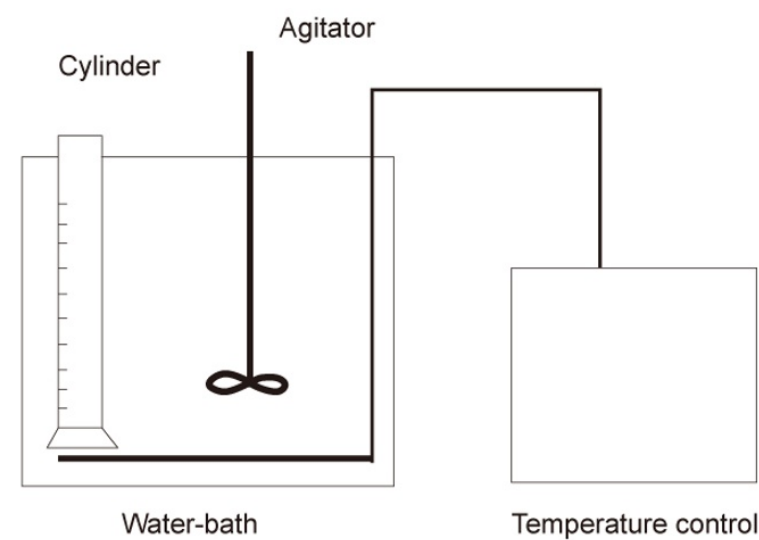

Fig. 1 Experimental setup for wax solubility measurement

In this paper, a quantity, the solubility ratio, was proposed to compare the difference of wax dissolved in the diesel oil and in the SNPA-diesel oil system. The solubility ratio defined as $R$ was obtained from the amount of wax dissolved in the diesel oil and in the SNPA-diesel oil system:

$$
R=m_{\text {SNPAs-D }} / m_{\mathrm{D}}
$$

where $m_{\mathrm{SNPAS}-\mathrm{D}}$ and $m_{\mathrm{D}}$ are the mass of dissolved wax in the SNPA-diesel oil system and in the diesel oil, respectively, g.

\section{Experimental results}

\subsection{The microstructure of SNPAs}

The TEM images of SNPAs (Fig. 2) shows that the size of

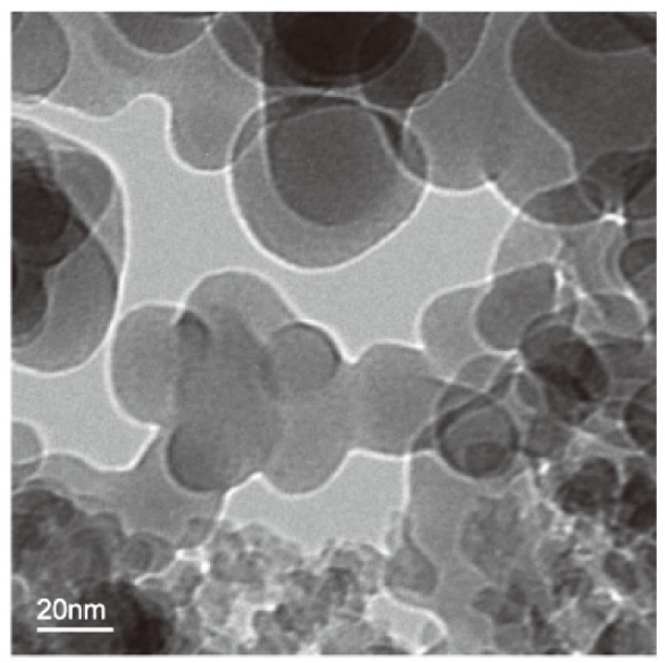

(b)

Fig. 2 The TEM images of SNPAs

the SNPAs was less than $100 \mathrm{~nm}$.

\subsection{The size distribution of SNPAs in diesel oil}

Fig. 3 shows the size distribution of SNPAs in diesel oil. It can be seen from Fig. 3 that the SNPAs had a diameter of 20$50 \mathrm{~nm}$ in diesel oil. This is consistent with the result from the TEM observation (Fig. 2).

\subsection{The viscosity of the SNPA-diesel oil system}

Fig. 4 presents the viscosity-temperature curves of the diesel oil and the SNPA-diesel oil system. The viscosity of the SNPAdiesel oil system was lower than that of diesel oil at the same temperature. So the addition of SNPAs to the diesel oil decreased the viscosity of diesel oil. This helps reduce the pressure required to inject the SNPA-diesel oil system into wells. 


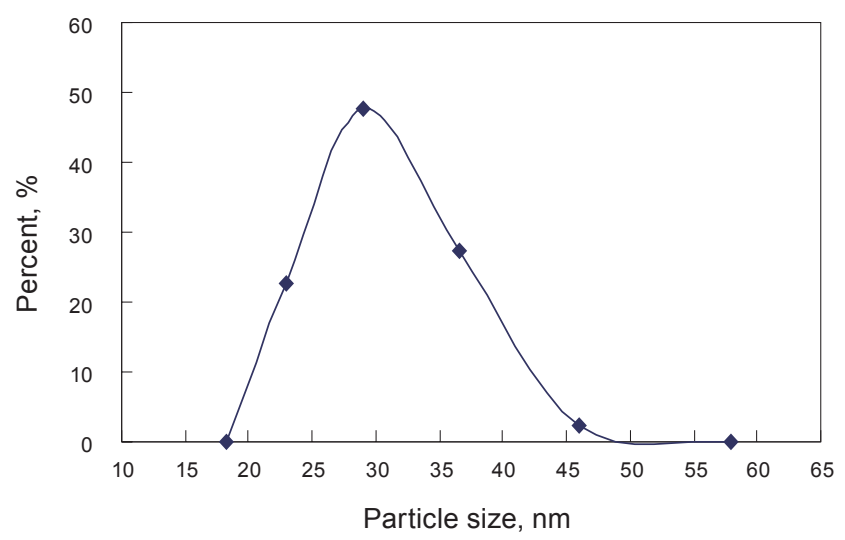

Fig. 3 The particle size distribution of SNPAs

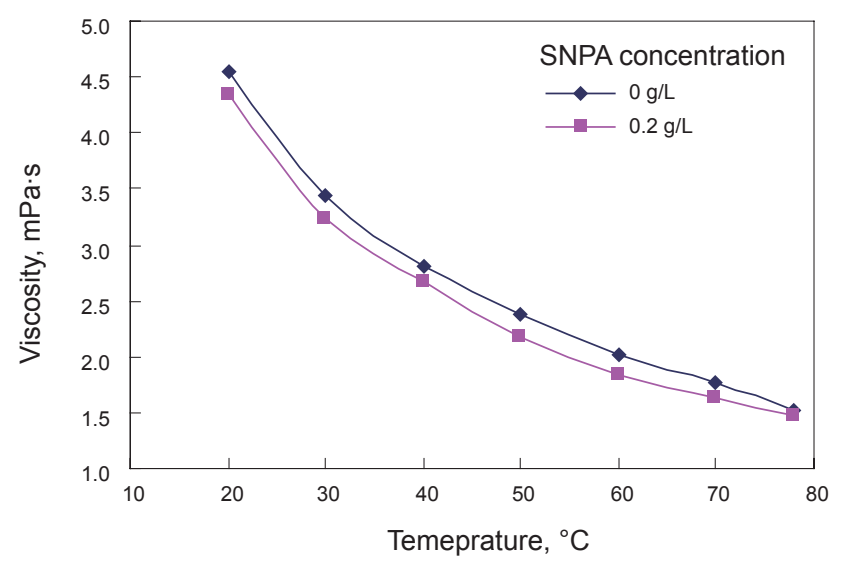

Fig. 4 The viscosity-temperature curves of the diesel oil and the SNPA-diesel oil system

\subsection{The dissolution of wax in the SNPA-diesel oil system}

Diesel oil is also used as a solvent to clean and remove the wax deposited in the wellbore. The effect of SNPAs on the wax solubility in the diesel oil was experimentally investigated at different temperatures.

Fig. 5 shows the solubility of wax in the diesel oil and in the SNPA-diesel oil system at $20-70{ }^{\circ} \mathrm{C}$. The wax solubility in the SNPA-diesel oil system was significantly higher than that in the diesel oil at $20-70{ }^{\circ} \mathrm{C}$. The solubility of wax in the SNPA-diesel oil system increased with an increase in SNPA concentration in the diesel oil. However, when the SNPA concentration increased from 3.0 to $5.0 \mathrm{mg} / \mathrm{L}$, the solubility of wax increased slightly.

Fig. 6 presents the plot of the solubility ratio versus temperature. The solubility ratio of wax was 1.5-7.5 when the temperature was $20-70{ }^{\circ} \mathrm{C}$. The solubility ratio of wax decreased with an increase in temperature. A comparison between Fig. 5 and Fig. 6 indicated that the wax solubility in the diesel oil and in the SNPA-diesel oil system increased with temperature, but the solubility ratio decreased with temperature.

\section{Discussion}

\subsection{The effect of SNPAs on wax dissolution}

The SNPAs are aggregates with an organic part and an

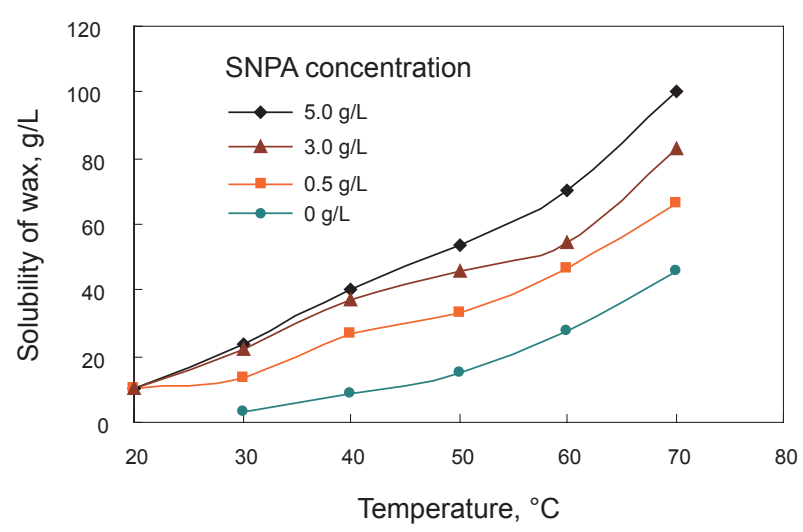

Fig. 5 The solubility of wax in diesel oil and SNPA-diesel oil systems

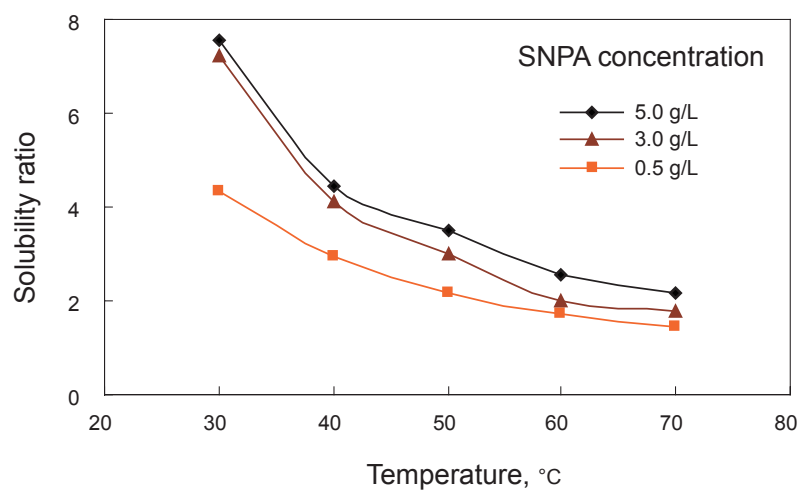

Fig. 6 The solubility ratios of wax at different temperatures

inorganic part. When SNPAs disperse in the diesel oil, their inorganic groups are at the nanometer level and have many unsaturated bonds, which very actively absorb wax crystals or act as wax crystal nuclei, thus the wax crystals will disperse effectively in the diesel oil with SNPAs. The organic groups in the SNPAs extend in the diesel oil. This helps prevent the aggregation and growth of the wax crystals. So the solubility of wax in the diesel oil increases with an increase in the SNPA concentration. The SNPA-diesel oil system would dissolve and then remove the wax deposited near the wellbore more efficiently than straight diesel oil. This would decrease the well injection pressure.

\subsection{The film change mechanism after SNPA injection}

In an oil reservoir, the water-wet rocks have surface where the molecular forces between water and the surface are greater than the molecular forces between oil and the same surface, so the pore and pore throat surfaces are covered by water films, as shown in Fig. 7. The water films will narrow the fluid-flow pathway, especially in the pore throats. This would block the fluid flow from the reservoir to the wellbore and then increase the injection pressure.

When the SNPA-diesel oil system is injected into the reservoir, the water films will be displaced by the SNPAdiesel oil system and new SNPA-diesel oil system films will be absorbed on the pore walls, as shown in Fig. 8. This will enlarge the fluid-flow pathway and decrease the injection pressure. 


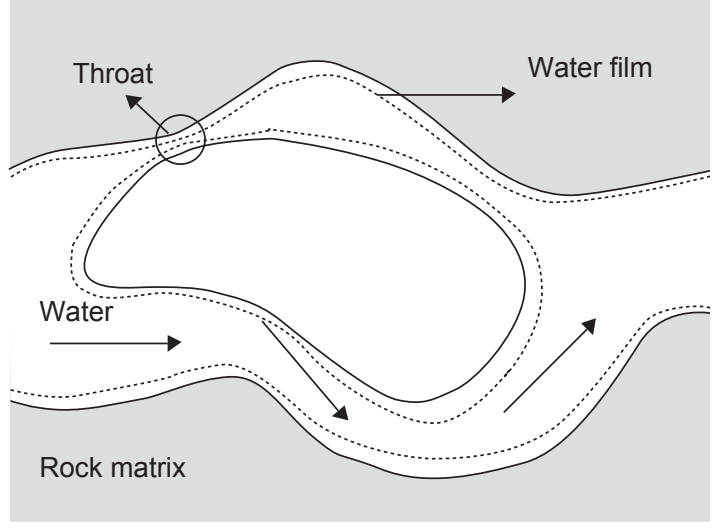

Fig. 7 The water films on walls of throats and pores in water-wet rocks

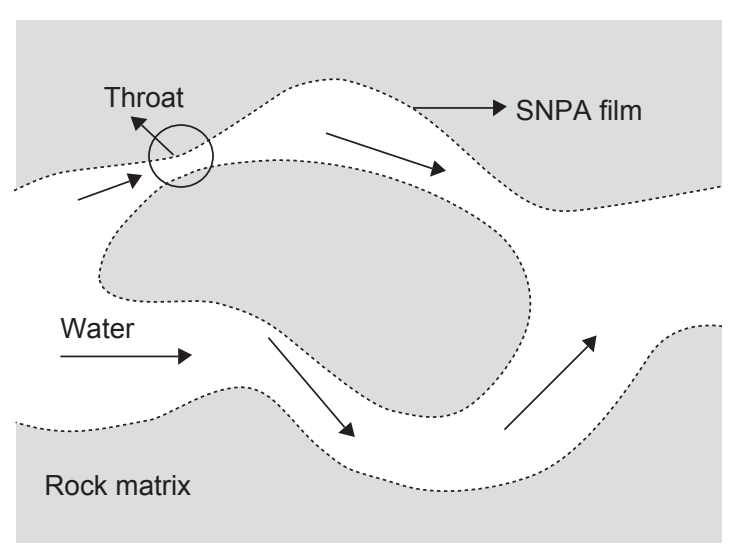

Fig. 8 The SNPA films on walls of throats and pores in water-wet rocks

\section{Conclusions}

1) The viscosity of SNPA-diesel oil system was lower than that of the diesel oil.

2) The solubility of wax in the diesel oil increased dramatically with the addition of SNPAs and the solubility ratio was 1.5-7.5.

3) The solubility of wax in the diesel oil increased with an increase in the concentration of SNPAs in the diesel oil.

4) The viscosity reduction, the film changes, and the increase in the solubility of wax may be the main reasons for injection pressure decrease.

\section{Acknowledgements}

The authors are grateful for the financial support from the National High-Technology Research and Development Program of China (No. 2004AA616160). The authors also express their appreciation to Mr. Ding Xiaohu and Song Xuehua for their work in this study.

\section{References}

Cao Z, Zhang Z J, Zhao Y F, et al. Preparation and characterization of $\mathrm{SiO}_{2}$ nanoparticles-water flooding enhancement agent of low permeability oil field. Chemistry Research. 2005. 16(1): 32-34 (in Chinese)

Chen X L, Qin J S and Li Z P. Studies of rock wettability alteration caused by surface modified lipophilic nanometric silica treatment. Oilfield Chemistry. 2005. 22(4): 328-331, 348 (in Chinese)

Cheng Y M, Li X H, Li Q H, et al. Preparation and performance of water-based nanometer polysilicon as augmented injection for oil field. Chemistry Research. 2006. 17(4): 56-59 (in Chinese)

Gao R M. Stimulation of water injection wells by using aqueous dispersion of active $\mathrm{SiO}_{2}$ nanopowder. Oilfield Chemistry. 2004. 21(3): 248-250 (in Chinese)

Hong X Z. The research and application of injection-increased technology about active nanometer material. Fault-Block Oil Gas Field. 2004. 11(3): 49-51 (in Chinese)

Huang Z Y, He Y, Yu N, et al. Study of FP-I clay stabilizer. Oil Drilling and Production Technology. 1995. 17(3): 55-57 (in Chinese)

Jin B J, Song G R, Li S G, et al. Screening clay stabilizers for reservoir anti-swelling treatment in water injection wells. Oilfield Chemistry. 2002. 19 (3): 244-247 (in Chinese)

Ju B S, Dai S G, Luan Z A, et al. A study of wettability and permeability change caused by adsorption of nanometer structured polysilicon on the surface of porous media. Paper SPE 77938 presented at the SPE Asia Pacific Oil and Gas Conference and Exhibition, 8-10 October 2002, Melbourne, Australia

Liu Y C, Li Z P and Chen X L. Research on polysilicon's solvent to organic material blocking. Oil Drilling and Production Technology. 2005. 27(6): 54-56 (in Chinese),

Lü G Z and Zhang J Q. A laboratory and application of nanometer polysilicon. Journal of Functional Materials. 2006. 37(7): 1110-1113 (in Chinese)

Lu X L, Lü G Z, Luan Z A, et al. Application of polysilicon in low permeability oil fields. Petroleum Exploration and Development. 2003. 30(6): 110-111, 122 (in Chinese)

Qing N, Zhang X L, Zhou J H, et al. Preparation and application of aminopolysiloxane soft agents. China Leather. 2000. 18(1): 12-16 (in Chinese)

Su X T, Yan J, Lü G Z, et al. Application of nanometer polysilicon in oil field development. Oil Drilling and Production Technology. 2002. 24(3): 48-51 (in Chinese)

Sun R Y and Wang L. Effect of nanometer polysilicon material on clay swelling. Journal of the Chinese Ceramic Society. 2008. 36(3): 391394,410

Yang L X, Guo W J, Xu Y W, et al. Application of blowdown stimulation technique with polysilicon nano-materials in Wendong oilfield. Journal of Jianghan Petroleum Institute. 2003. 25(Suppl A): 105-106 (in Chinese)

Yi H, Sun H H, Li F X, et al. Decompression and augmented injection theories research of nanometer polysilicon in oilfield water flood development. Natural Science Journal of Harbin Normal University. 2005. 21(6): 66-69 (in Chinese)

Yuan L, Cao Q F and Wang J H. Laboratory research on the pretreatment of the swelled clay shrinkage agent in oilfield injection. Small Hydrocarbon Reservoirs. 2006. 11(3): 42-45 (in Chinese)

Zhang J C, Cao X L, Tang Z H, et al. Experiment of polysilicon material for improving waterflooding effect in low permeability oil reservoirs. Petroleum Geology and Recovery Efficiency. 2003. 10(4): 59-60 (in Chinese)

(Edited by Sun Yanhua) 